\title{
Flow resistance of partially flexible vegetation: $A$ full-scale study with natural plants
}

\author{
Enrico Antonio Chiaradia, Claudio Gandolfi, Gian Battista Bischetti \\ Department of Agricultural and Environmental Sciences, Università degli Studi di Milano, Italy
}

\begin{abstract}
Riparian vegetation plays a crucial role in riverine ecosystems, providing many types of benefits to nature and humanity. However, a high vegetation density can reduce the conveyance capacity of a watercourse, particularly in the case of shrubs, which are very common within riverbeds and widely used in river and channel restoration works. In this paper, we study the influence of three species of shrubs (white and goat willows and black alder) on the hydraulic resistance factor of a real-scale channel under controlled flow conditions. A system for the anchorage of shrubs to the channel bed allowed us to carry out repeated experiments with the three plant species and with varying plant densities and flow rates. The experimental results provided a range of values for the additional contribution of the vegetation to the hydraulic resistance factor from 0.004 to $0.071 \mathrm{~m}^{-1 / 3} \mathrm{~s}$, in terms of Manning's coefficient. This variability is related to the vegetation setup (plant species and density) but also to the increasingly hydrodynamic configuration assumed by plants at higher flow velocities and submergence ratios. We found that these factors can be summarised quite effectively by the product of elasticity (E), plant density (M), and plant area index (PAI). At small (E.M.PAI) values $\left(<10^{8}\right)$ the
\end{abstract}

Correspondence: Enrico Antonio Chiaradia, Department of Agricultural and Environmental Sciences, Università degli Studi di Milano, via Celoria 2, 20133 Milano, Italy.

E-mail: enrico.chiaradia@unimi.it

Key words: Vegetation; flow resistance; hydraulic roughness; riverbank stabilisation.

Acknowledgements: the research was conducted under the Monaco Project granted by DG Agricoltura of Regione Lombardia (Programma regionale di ricerca in campo agricolo 2001-2003). We thank Ettore Fanfani, Fausto Cremascoli, Attilio Lucchini, Adolfo Rocca, and Luca, of Consorzio Muzza Bassa Lodigiana for their fundamental contribution to the building of the experimental channel and to the tests conduction.

Received for publication: 29 June 2018.

Accepted for publication: 8 May 2019.

(C) Copyright E.A. Chiaradia et al., 2019

Licensee PAGEPress, Italy

Journal of Agricultural Engineering 2019; L:885

doi:10.4081/jae.2019.885

This article is distributed under the terms of the Creative Commons Attribution Noncommercial License (by-nc 4.0) which permits any noncommercial use, distribution, and reproduction in any medium, provided the original author(s) and source are credited. resistance coefficient is less than 0.01 , while it increases of up to one order of magnitude when (E.M.PAI) exceeds $10^{10}$. Furthermore, our results show a distinct two-stage trend of the value of the additional contribution to the $n$ coefficient of a given vegetation setup at varying velocities and submergence levels, with values decreasing when a threshold of velocity and submergence ratio is exceeded. The position of this threshold point appears to be related to the geometrical and mechanical characteristics of the plants. Although our experiments do not provide enough data to identify a functional relationship between $\mathrm{n}$ and specific characteristics of the plants and of the flow, they show that the effect of shrubs on hydraulic resistance is highly variable with the flow conditions and that the conveyance capacity may be significantly larger than expected.

\section{Introduction}

Riparian vegetation plays a crucial role in riverine ecosystems, providing many benefits to nature and humanity (Bennet and Simon, 2004). Plants on riverbanks and floodplains, in fact, provide habitats and food resources for wildlife, improve geomorphologic stability and enhance aesthetic and recreational value (Pusey and Arthington, 2003; Merritt et al., 2010). As a consequence, conservation and improvement of native riparian plants are frequently recommended by environmental agencies for river management and bank protection (e.g., FISRWG, 1998), both by planting and by adopting soil bioengineering techniques. At the same time, howev$\mathrm{er}$, it is equally widely recognised that riverine vegetation, especially shrubs and bushes, can reduce the conveyance capacity of a stream due to the increased hydraulic resistance and of the reduction of hydraulic sections (e.g., Chow, 1959 p. 102).

In recent years, an increasing number of studies have been carried out to investigate the relationship between different types of vegetation and flow characteristics. Some of these studies have addressed fully flexible and fully submerged vegetation, such as grass and macrophytes (Temple, 1999; Yen, 2002; Carollo et al., 2005; Kirkby et al., 2005; Bal et al., 2011; Nepf, 2012; Li et al., 2014; Bebina Devi and Kumar, 2016; Errico et al., 2018). The results that were obtained are robust, but their field of application is quite restricted (mainly grassed waterways and narrow streams). When shrubs and small riparian trees are concerned, as for example in many stream restoration works or in maintaining riparian vegetation on stream banks, their applicability is very limited.

Other studies focused on rigid non-submerged vegetation, typically trees (Ming and Shen, 1973; Arcement and Schneider, 1987; Yen, 2002; Järvelä, 2004; Kothyari et al., 2009), providing a sound framework to consider its effect on flood propagation over floodplains, but they are of little use when semi-natural, mixed riverbank vegetation is at present.

Fewer studies have considered non-rigid and non-submerged 
or just submerged plants. Quite often, they were based on hydraulic experiments conducted in laboratory flumes, with artificial elements mimicking the real vegetation, owing to the practical difficulties involved in using real plants (Wu et al., 1999; Yen, 2002; Righetti and Armanini, 2002; Stone and Shen, 2002; Wilson et al., 2003; Musleh and Cruise, 2006; Yagci et al., 2010; Jalonen et al., 2013). When real vegetation was used, the experiments were generally conducted in small-scale laboratory flumes with young plants or tiny portions of green vegetation (Yen, 2002; Armanini et al., 2005; Rhee et al., 2008; Righetti, 2008; Chiaradia, 2012; Västila et al., 2013). Only in very few cases have the experiments involved fully developed vegetation in real flow conditions (Yen, 2002; Freeman et al., 2000; Västila et al., 2013). Although smallscale experiments are fundamental to investigate the relationships between plants and flow under rigorously controlled conditions, scale issues concerning the mechanical and geometrical properties of plants as well as the hydraulic conditions can severely affect the results. In fact, the shape of shrub vegetation dynamically varies as a response to the drag force exerted by the flow. Therefore, the mutual interaction between flow conditions and vegetation is strongly related to the characteristics of plants, such as branching, foliation and stiffness (e.g., Chiaradia, 2012), which are very difficult to reproduce in small-scale models. Thus, full-scale experiments are highly relevant and can provide new insights into the relationships between shrub vegetation and flow. Unfortunately, such experiments require large channels and huge volumes of water, plants and labour, and they are subject to more limitations than small-scale tests (e.g., repeatability, seasonality, difficulties in measuring and controlling the hydraulic variables).

In this study, we present and discuss the results of a number of full-scale experiments conducted in a large channel equipped with real branches of riparian vegetation (Salix and Alnus spp.), considering a wide range of discharge values (up to $5 \mathrm{~m}^{3} / \mathrm{s}$ ) and various plant densities, similar to those that can be observed in nature. The aim is to contribute to the knowledge of the mutual influence between shrub vegetation and flow resistance, overcoming some of the limitations affecting small-scale experiments and unnatural plant prototypes.

\section{Materials and methods}

\section{The experimental channel}

The experimental channel was obtained by adapting an existing ditch, which connects a large pumping station for land reclamation to the receiving water body (the Adda river).

Figure 1 shows a plan view of the experimental channel. A sluice gate at the channel inlet allows the control of the flow rate (Figure 1 and 2) according to the water level upstream of the gate, based on a theoretical flow-rating curve verified by actual discharge measurements. A floating gage provides continuous monitoring of the water level. The channel is $130 \mathrm{~m}$ long and can be split into six different reaches. The central reach (reach 4 in Figure 1 ) is the one in which vegetation can be placed; it is $40 \mathrm{~m}$ long with a bottom slope of 0.01 , and it has a trapezoidal cross-section with a base width of $2 \mathrm{~m}$ and a side slope of $1.5 \mathrm{H}: 1 \mathrm{~V}(\mathrm{H}=$ horizontal, $\mathrm{V}=$ vertical). The banks are lined with boulders, and the concrete bottom hosts a network of cylindrical plastic housings ( $0.4 \mathrm{~m}$ spacing) that allow the vegetation branches to be firmly anchored (Figure 2). Five stilling wells are distributed along this reach at 10 $\mathrm{m}$ intervals, permitting water depth measurements by floating gages. The central reach is preceded by three shorter reaches $(1,2$ and 3 in Figure 1), in which the inflow from the inlet gate is smoothed to facilitate the attainment of steady state conditions at the beginning of the central reach. Finally, two terminal reaches ( 5 and 6 in Figure 1) gradually connect the central reach with the receiving water body. It is worth noting that through the adaptation of an existing structure, we obtained a full-scale experimental channel with a very small investment, compared with laboratory facilities of similar size. The main necessary works consisted of lining the bed of the transition and central reaches ( 3 and 4), creating a branch-anchoring system based on cylindrical plastic housings inserted into the concrete layer of the central reach, and installing the stilling wells along the same reach (Figure 2). However, our experimental facility suffers from some limitations compared with laboratory channels. In particular, we could not directly observe and measure the processes and variables that can

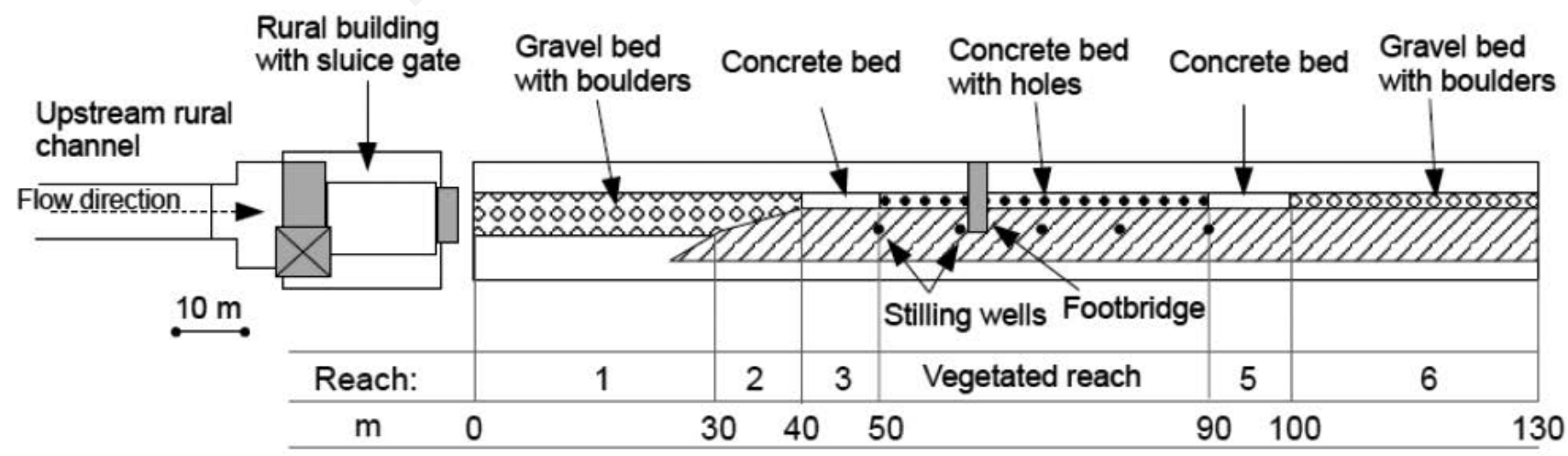

Figure 1. Plan view of the experimental channel. Water is supplied by an upstream channel and the inlet flow is controlled by a sluice gate installed in a rural building. The experimental channel consists of: two reaches $(1,2)$, where the inlet flow is smoothed, that are gradually linked to a transition reach (3) with the same geometry and linings of the following central reach (4) where vegetation can be placed, and two final reaches ( 5 and 6 ) linking the canal to the final receptor (a river). 
be generally monitored in laboratory conditions, such as velocity profiles and plant deflection dynamics.

\section{Experimental activity}

The experimental activity that we carried out involved three riparian species: black alder (Alnus glutinosa L.), white willow (Salix alba L.) and goat willow (Salix caprea L.). Black alder and goat willow can be considered brush species, especially in the younger forms, that are typical of riverbanks (Eschenbach and Kappen, 1999; Dušek and Květ, 2006), since only with aging and under favourable environmental conditions they become medium and small trees, respectively (Claessens et al., 2010; Dušek and Květ, 2006). White willow is a riparian tree, and we used its branches as representative of Salix spp in general.

For each botanical species, we considered different vegetation setups in the central reach of the experimental channel - i.e., different combinations of plant species, plant density (in terms of number of plants per square meter), vegetation density and foliage status. The activity was organised in sessions, in which a fixed vegetation setup was maintained in the channel, and different experiments were carried out by changing the flow discharge.

The vegetation setups were assembled using freshly cut branches of willow and alder, randomly placed in the central reach. The mechanical and geometrical properties of the vegetation were measured shortly before the sessions. For each plant species, the sessions were carried out in sequence, from the setup with the highest vegetation density to the one with the lowest. The new setup was obtained from the previous one by removing some plants, until the desired vegetation density was reached.

During each experiment, the flow rate in the channel was kept constant - by continuously adjusting the sluice gate at the channel inlet - to guarantee stationary conditions for the time necessary to take the measurements.

\section{Characterisation of vegetation}

The mechanical properties were measured through the cantilever method (Chiaradia, 2012) described by Freeman et al. (2000) and applied to the entire plant. Accordingly, the modulus of elasticity $E\left(\mathrm{~N} / \mathrm{m}^{2}\right)$ was estimated as:

$$
E=\frac{F \cdot b^{3}}{3 \cdot I \cdot \Delta}
$$

where $F$ is the load attached at height $b(\mathrm{~m})$, generating a bending of the plant stem D (m).

The stem structure was represented in a simplified form as a cylinder of diameter $D_{S}(\mathrm{~m})$, and the moment of inertia $I\left(\mathrm{~m}^{4}\right)$ was calculated as:

$I=\frac{\pi D_{S}^{4}}{64}$

Measurements of the modulus of elasticity and moment of inertia, along with plant height and diameter, were taken on thirty plants for each species before implantation in the channel bed. A summary of the measurements is reported in Table 1.

Before running each session, the stem diameter and the undeflected plant height were measured for at least thirty plants, whereas the plant density (number of stems per square meter) and the above- and below-canopy photosynthetically active radiation (PAR) values were measured at thirty or more different spots. The PAR values, representing the portion of the light spectrum that plants can use for photosynthesis, were measured using an Accupar LP 80 ceptometer (Chiaradia, 2012). The difference between complementary above- and below-canopy PAR values was used to estimate the plant area index (PAI), which represents the sum of total surface areas of all the phytoelements, i.e. stems and green leaves, per unit ground area (Chiaradia, 2012). We believe that PAI index is more representative of the actual vegetation biomass than the leaf area index (LAI), which considers only the foliage in case of small trees and bushes. A summary of the characteristics of the vegetation used in each session is reported in Table 2.

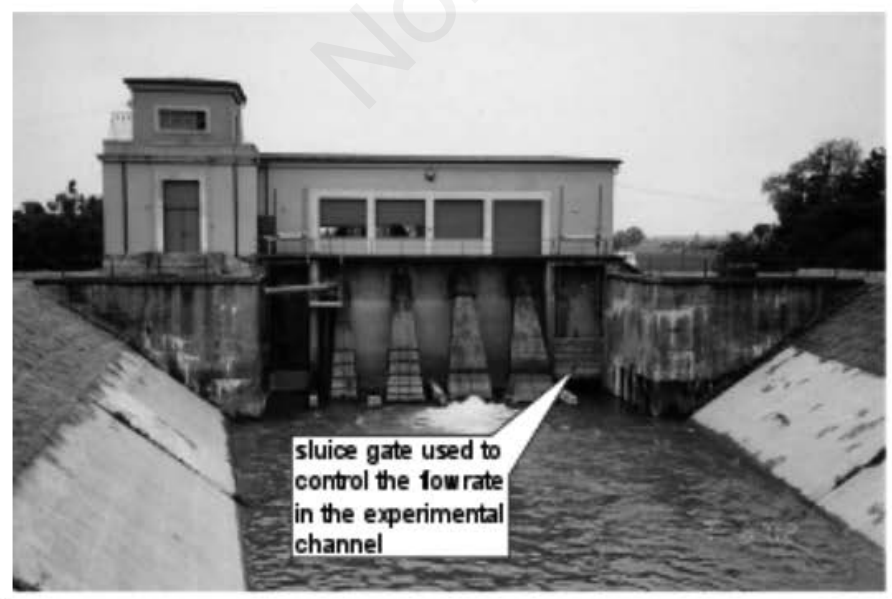

$\mathbf{A}$

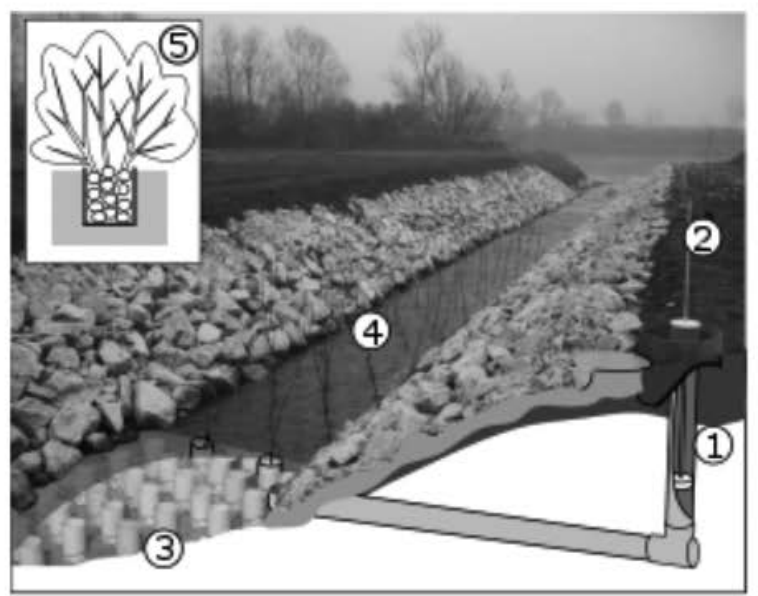

$\mathbf{B}$

Figure 2. A view of the rural pumping station (A) and of the vegetated reach of the experimental channel (B) showing a schematic representation of the apparatus for the water depth measurement in a section (stilling well, 1 , and float, 2 ) and of the cylindrical plastic housings inserted in the concrete bed (3) for the anchorage of the branches (4) using stones as weight (5). 


\section{Characteristics of the experimental sessions}

We carried out a total of 9 sessions: 4 with white willow (Salix alba L.) (sessions from SA1 to SA4), 4 with goat willow (S. caprea L.) (sessions from SC1 to SC4), and 1 only with black alder ( $A$. glutinosa L.) (session AG1) (Table 2). One additional session was conducted without any vegetation (NV session) to determine the background value of the resistance factor. The number of experiments per session ranged from a minimum of 5 (NV session) to a maximum of 10 (SA3 session), with a total of 66 experiments (Table 3).

The geometrical and mechanical characteristics of plants used in the sessions are summarised in Table 1. Stem diameter values are similar for each species (approximately $1.4 \mathrm{~cm}$ ), whereas $A$. glutinosa differs from the others in terms of undeflected plant height, $h_{\text {veg }}$. The modulus of elasticity of $S$. caprea $(1.9 \mathrm{MPa})$ is greater than those of $S$. alba $(1.5 \mathrm{MPa})$ and A. glutinosa, which is the lowest $(1 \mathrm{MPa})$. This finding is also reflected on the EI term (Elasticity moment of Inertia product): the willow plants showed similar EI values ( $4 \mathrm{Nm}^{2}$ for $S$. alba and $4.4 \mathrm{Nm}^{2}$ for $S$. caprea), whereas alder plants had the lowest value $\left(0.7 \mathrm{Nm}^{2}\right)$.

The aboveground morphology was different among the species: the alder plants consisted of a single stem with few braches in the upper half; in contrast, the willows had branched arms along the entire length of the stem and were fairly uniform in size.

The actual vegetated length of the channel varied among the sessions from 20 to $40 \mathrm{~m}$, to obtain the desired experimental setting. The plant density varied from 14.8 to 2.6 stems per square meter in the SA sessions and from 17.3 to 5.4 in the SC sessions.

The PAI varied from a minimum value of 0.43 to a maximum of 1.17 (-) in the SA sessions and from 0.09 to 1.83 (-) in the SC sessions (Table 2). In the case of AG, only one vegetation density of 2.5 plants per square meter and a PAI index of 0.02 (-) were tested. Note that because PAI depends on both stems and leaves, it may significantly change for the same plant density according to the number of leaves: as an example, the PAI value of the vegetation setup of session SC2 was approximately one third of that of $\mathrm{SC} 1$, in spite of the fact that the two setups had the same density, with the only difference being the number of leaves.

Normally, each session was completed within $24 \mathrm{~h}$, with the same branches in the channel maintained between experiments. The large dimensions of the channel and the high flow rates permitted fully turbulent flow conditions to be achieved in all experiments, dynamically and kinematically similar to those occurring in

Table 1. Plant characteristics.

\begin{tabular}{|c|c|c|c|c|}
\hline $\begin{array}{l}\text { Species } \\
\text { Description }\end{array}$ & & $\begin{array}{l}\text { Alnus glutinosa }(A G) \\
\text { Young plants in pots }\end{array}$ & $\begin{array}{l}\text { Salix alba (SA) } \\
\text { Just-cut branches }\end{array}$ & $\begin{array}{l}\text { Salix caprea (SC) } \\
\text { Just-cut branches }\end{array}$ \\
\hline Plant height, $h_{\text {veg }}(\mathrm{m})$ & $\begin{array}{l}\text { Min } \\
\text { Mean } \\
\text { Max } \\
\text { SD. }\end{array}$ & $\begin{array}{l}0.90 \\
1.70 \\
2.20 \\
0.34\end{array}$ & $\begin{array}{l}0.95 \\
1.47 \\
2.20 \\
0.32\end{array}$ & $\begin{array}{l}0.80 \\
1.52 \\
2.40 \\
0.39\end{array}$ \\
\hline Plant diameter, DS (m) & $\begin{array}{l}\text { Min } \\
\text { Mean } \\
\text { Max } \\
\text { SD }\end{array}$ & $\begin{array}{l}0.005 \\
0.015 \\
0.020 \\
0.004\end{array}$ & $\begin{array}{l}0.009 \\
0.014 \\
0.019 \\
0.003\end{array}$ & $\begin{array}{l}0.007 \\
0.014 \\
0.025 \\
0.004\end{array}$ \\
\hline Elasticity, E x10 $\left(\mathrm{N} / \mathrm{m}^{2}\right)$ & $\begin{array}{l}\text { Min } \\
\text { Mean } \\
\text { Max } \\
\text { SD. }\end{array}$ & $\begin{array}{c}5.3 \\
10.4 \\
19.5 \\
5.3\end{array}$ & $\begin{array}{c}5.4 \\
15.1 \\
29.6 \\
7.3\end{array}$ & $\begin{array}{c}2.8 \\
19.1 \\
48.6 \\
10.6\end{array}$ \\
\hline $\mathrm{EI}\left(\mathrm{Nm}^{2}\right)$ & $\begin{array}{l}\text { Min } \\
\text { Mean } \\
\text { Max } \\
\text { SD }\end{array}$ & $\begin{array}{c}0.31 \\
0.7 \\
1.4 \\
0.4\end{array}$ & $\begin{array}{c}0.18 \\
4.0 \\
12.5 \\
3.9\end{array}$ & $\begin{array}{c}0.12 \\
4.4 \\
25.6 \\
5.6\end{array}$ \\
\hline
\end{tabular}

Table 2. Characteristics of the session.

\begin{tabular}{|c|c|c|c|c|c|}
\hline Session & Vegetation description & $\begin{array}{c}\text { Vegetated reach } \\
\text { length (m) }\end{array}$ & $\begin{array}{l}\text { Plant density } \\
\text { (\#plants/m²) }\end{array}$ & $\begin{array}{l}\text { Plant mean } \\
\text { diameter }(\mathrm{cm})\end{array}$ & PAI (-) \\
\hline NV & No-vegetation (reference condition) & - & - & - & - \\
\hline AG1 & Leafless plants & 40 & 2.5 & 15.1 & 0.02 \\
\hline SAl & Leafless branches & 20 & 14.79 & 13.9 & 0.59 \\
\hline SA2 & Branches with few leaves at the top of stems & 40 & 2.625 & 13.9 & 0.6 \\
\hline SA3 & Branches with few leaves at the top of stems & 20 & 2.625 & 13.9 & 0.43 \\
\hline SA4 & Branches with a lot of leaves at the top of stems & 20 & 3.75 & 19,9 & 1.17 \\
\hline $\mathrm{SCl}$ & Just-cut branches with many, uniformly distributed leaves & 30 & 18.02 & 15.2 & 1.83 \\
\hline SC2 & Leafless branches & 30 & 18.02 & 12.4 & 0.55 \\
\hline SC3 & Leafless branches & 40 & 11.7 & 11.9 & 0.34 \\
\hline SC4 & Leafless branches & 40 & 5.4 & 10.9 & 0.09 \\
\hline
\end{tabular}


natural rivers (e.g., Babaeyan-Koopaei et al., 2002; Västila et al., 2013) and similar to those experimented by Freeman et al. (2000). In fact, the Reynolds number $(R e=V R / v$; Yen, 2002) and velocity values were in the range of $0.2-1.010^{6}(-)$ and $0.6-2.4 \mathrm{~m} / \mathrm{s}$, respectively (Table 3 ).

\section{Estimation of the resistance due to vegetation}

Isolating the effect of vegetation from the total resistance of the vegetated reach is not straightforward. The simplest and most widely used approach consists of splitting up the total resistance into different additive components (e.g., Freeman et al., 2000; Yen, 2002; Sellin et al., 2003; Green, 2005; Rhee et al., 2008; Jalonen et al., 2013; Västilä et al., 2013). In our case, two components are relevant: the resistance of the non-vegetated wetted perimeter, expressed by the roughness coefficient $n_{b}$, and the additional contribution of the vegetation, expressed by the roughness coefficient $n_{\text {veg. }}$. Therefore, we assumed that the total roughness coefficient $n$ is given by:

$n=n_{b}+n_{v e g}$

Both $n_{b}$ and $n_{v e g}$ are expected to change with varying water level in the channel, given the heterogeneity of the channel section and the dynamic behaviour of flexible vegetation. Therefore, we used the observations collected in each of the five experiments with no vegetation and in each of the 61 experiments with vegetation, described in the previous section, to derive as many values of $n_{b}$ and $n_{v e g}$ as possible. In fact, for each experiment, the measurements of $Q$ and the water elevation $y_{i}$ at the control sections in steady-state conditions were available, similar to other studies on just submerged vegetation (e.g., Rhee et al., 2008; Righetti, 2008; Västilä et al., 2013). This allowed us to estimate the unknown value of the total Manning coefficient $n$ through an iterative procedure that minimises the root mean square error (RMSE) between the measured water elevations and the values obtained at the same sections by the numerical integration of the energy equation between the initial and final sections of the central reach.

The discrete form of the energy equation for two consecutive sections, $i$ and $i+1$, is:

$$
\frac{H_{i+1}-H_{i}}{\left(x_{i+1}-x_{i}\right)}=-\frac{\left(S_{f i}-S_{f_{i+1}}\right)}{2}
$$

where $H_{i}(\mathrm{~m})$ is the energy level at section $i, S_{f i}(-)$ is the slope of the energy line at the same section, and $x_{i}$ is the coordinate of the section along the channel. Standard step method (SSM) was applied with $1 \mathrm{~m}$ spacing between sections. The channel geometry was derived from direct survey at a number of sections (approximately every $5 \mathrm{~m}$ ) and from linear interpolation for intermediate sections.

The energy level in section $i$ is given by:

$$
H_{i}=z_{i}+h_{i}+\alpha \frac{V_{i}^{2}}{2 g}=y_{i}+\alpha \frac{V_{i}^{2}}{2 g}
$$

where $z_{i}$ is the bed elevation (m); $h_{i}$ is the flow depth (m); $\alpha$ is the Coriolis coefficient, which is assumed to be 1 because of the fully turbulent regime of the flow in the channel; $g\left(\mathrm{~m} / \mathrm{s}^{2}\right)$ is the gravitational acceleration constant; $V_{i}(\mathrm{~m} / \mathrm{s})$ is the mean flow velocity; and $y_{i}$ is the water elevation in the channel $(\mathrm{m})$.

The friction slope is given by:

$S_{f}=\left(\frac{n Q}{A R^{2 / 3}}\right)^{2}$

where $n\left(\mathrm{~m}^{1 / 3} / \mathrm{s}\right)$ is the Manning coefficient, $Q\left(\mathrm{~m}^{3} / \mathrm{s}\right)$ is the discharge, $A\left(\mathrm{~m}^{2}\right)$ is the wetted area of the section, and $R(\mathrm{~m})$ is the hydraulic radius.

At each step of the estimation procedure, the energy profile corresponding to the current value of $n$ is computed using the SSM (Subhash, 2001) to solve the integration problem, and the RMSE value of the observed vs. simulated water levels is then computed. The procedure terminates when the variation of the value of $n$ between two subsequent steps is less than 0.001 , which corresponds to an accuracy in the discharge estimation $>97 \%$, which can be considered acceptable for practical use and consistent with the experimental setup.

The five values of the Manning coefficient of the non-vegetated wetted perimeter obtained from the experiments of the NV session were then related to the corresponding average water level in the experimental reach, $\bar{h}$, to obtain the $n_{b}(\bar{h})$ relationship to be used with Equation (3) to derive the $n_{v e g}$ values for the experiments with vegetation. Because the section is non-homogenous, with higher roughness of the boulder banks than that of the concrete

\begin{tabular}{|c|c|c|c|c|c|c|c|c|c|c|c|}
\hline \multirow[t]{2}{*}{ Session } & \multirow{2}{*}{$\begin{array}{l}\text { Number of } \\
\text { experiments }\end{array}$} & \multicolumn{2}{|c|}{ Flow rate $\left(\mathrm{m}^{3} / \mathrm{s}\right)$} & \multicolumn{2}{|c|}{ Water level (m) } & \multicolumn{2}{|c|}{ Velocity $(\mathrm{m} / \mathrm{s})$} & \multicolumn{2}{|c|}{$n_{\mathrm{eq}}\left(\mathrm{m}^{-1 / 3} \mathrm{~s}\right)$} & \multicolumn{2}{|c|}{$\operatorname{Re}(-)$} \\
\hline & & Min & Max & Min & Max & Min & Max & Min & Max & Min & Max \\
\hline NV & 5 & 1.0 & 5.0 & 0.24 & 0.63 & 1.69 & 2.68 & 0.022 & 0.025 & $340 \cdot 10^{3}$ & $1139 \cdot 10^{3}$ \\
\hline AG1 & 6 & 0.5 & 3.0 & 0.18 & 0.51 & 1.22 & 2.08 & 0.025 & 0.031 & $183 \cdot 10^{3}$ & $763 \cdot 10^{3}$ \\
\hline SAl & 7 & 1.0 & 3.0 & 0.48 & 0.86 & 0.78 & 1.09 & 0.070 & 0.092 & $275 \cdot 10^{3}$ & $562 \cdot 10^{3}$ \\
\hline SA2 & 7 & 0.75 & 4.45 & 0.34 & 0.83 & 0.85 & 1.62 & 0.049 & 0.062 & $227 \cdot 10^{3}$ & $829 \cdot 10^{3}$ \\
\hline SA3 & 10 & 0.50 & 5.0 & 0.25 & 0.88 & 0.79 & 1.66 & 0.049 & 0.065 & $165 \cdot 10^{3}$ & $887 \cdot 10^{3}$ \\
\hline SA4 & 8 & 0.50 & 5.0 & 0.22 & 0.85 & 0.97 & 1.80 & 0.032 & 0.060 & $174 \cdot 10^{3}$ & $955 \cdot 10^{3}$ \\
\hline $\mathrm{SCl}$ & 8 & 0.50 & 5.0 & 0.35 & 0.99 & 0.56 & 1.47 & 0.061 & 0.093 & $155 \cdot 10^{3}$ & $840 \cdot 10^{3}$ \\
\hline SC2 & 8 & 0.50 & 5.0 & 0.31 & 0.91 & 0.65 & 1.66 & 0.051 & 0.080 & $162 \cdot 10^{3}$ & $901 \cdot 10^{3}$ \\
\hline SC3 & 8 & 0.50 & 5.0 & 0.26 & 0.82 & 0.77 & 1.84 & 0.042 & 0.055 & $163 \cdot 10^{3}$ & $934 \cdot 10^{3}$ \\
\hline SC4 & 8 & 0.50 & 5.0 & 0.18 & 0.89 & 1.16 & 2.37 & 0.027 & 0.041 & $181 \cdot 10^{3}$ & $1063 \cdot 10^{3}$ \\
\hline
\end{tabular}

Table 3. Hydraulic characteristics of each experimental session ( $\mathrm{n}_{\mathrm{eq}}=$ total Manning's roughness coefficient, Re = Reynold's number). 
bottom, the relationship is expected to be nonlinear, according to the most widely recognised methods to estimate the total roughness of composite sections (e.g., Yen, 2002). Therefore, we used a power function to interpolate the roughness vs. water level rating curve, obtaining

$n_{b}=0.027 \bar{h}^{0.142} \quad\left(\mathrm{R}^{2}=0.90\right)$

where is the average water depth.

Almost the same relationship is obtained by applying the Einstein-Horton method with roughness coefficient values that are consistent with the section characteristics $\left(0.31 \mathrm{~m}^{-1 / 3} \mathrm{~s}\right.$ and $0.21 \mathrm{~m}^{-}$ ${ }^{1 / 3} \mathrm{~S}$ for the banks and bottom, respectively, based on Chow, 1959).

\section{Results}

The results are presented in terms of Manning's coefficient as a function of the product $V R\left(\mathrm{~m}^{2} / \mathrm{s}\right)$, proportional to the Reynolds number, the ratio $h / h_{\text {veg }}(-)$ between water depth and undeflected vegetation height and the plant Reynolds number introduced by Armanini et al. (2005) and Righetti (2008):

$R e_{p}=V D_{s} / v$

where $D_{s}$ is the average stem diameter, and $v$ is the kinematic viscosity.

\section{Alnus glutinosa session}

The results of the 6 Alnus glutinosa (AG) experiments are shown in Figure 3. It can be noted that the presence of low-density leafless plants characterised by a single stem and few branches in the upper half did not greatly impact the hydraulic resistance. The range of the additional Manning coefficient, $n_{\mathrm{veg}}$ (obtained from Eq. 8), is within the range specified by Arcement and Schneider (1987) as small and typical of a tree seedling growing where the average flow depth is three times the height of the vegetation.

Although the variation of $n_{\mathrm{veg}}$ with hydraulic conditions is

AG
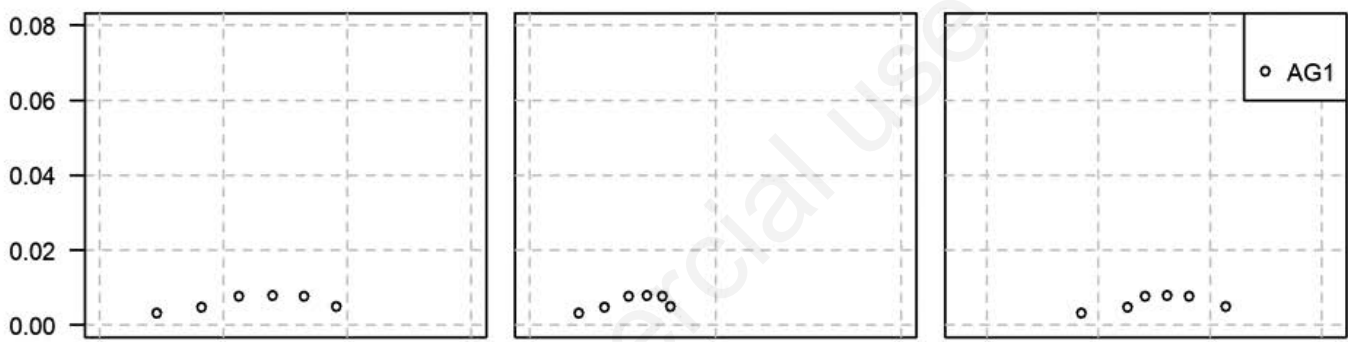

SA
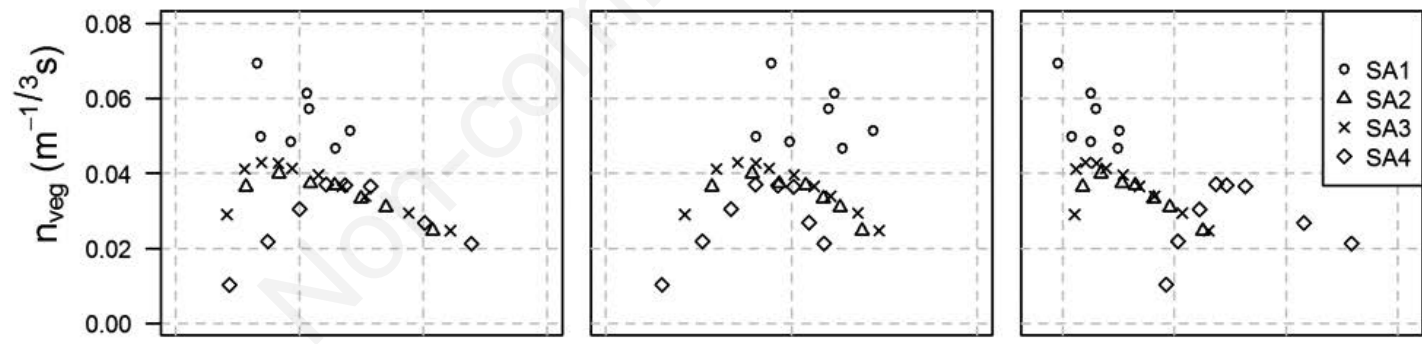

$\mathrm{SC}$
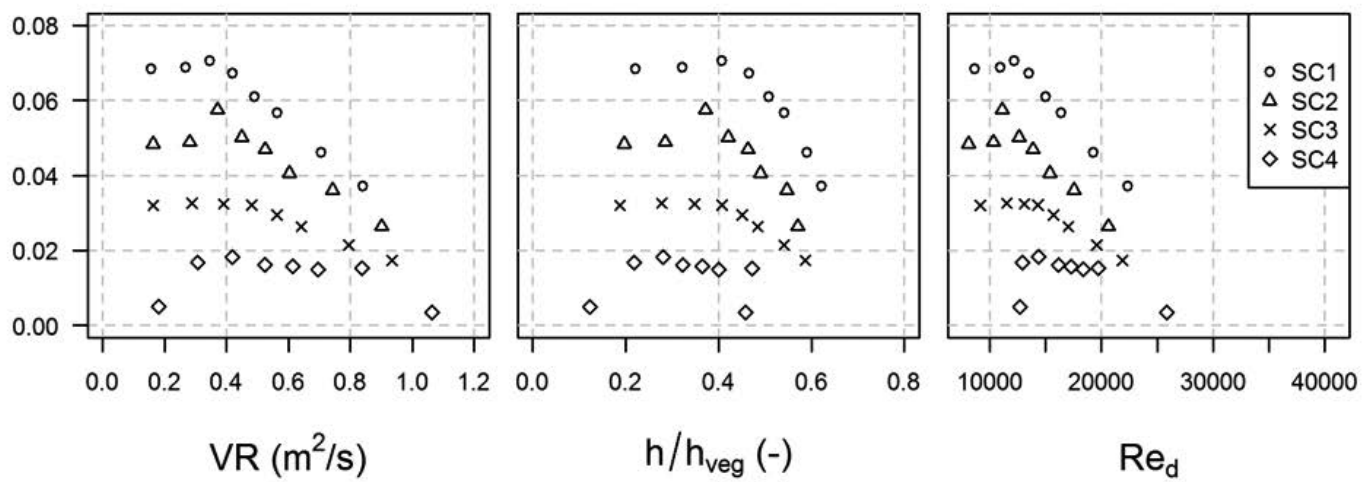

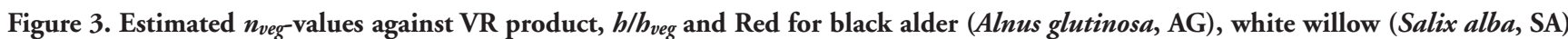
and goat willow (Salix caprea, SC). 
small, it showed a moderately rising trend with $V R, h / h_{v e g}$ and $R e_{p}$ followed by a falling limb. The maximum $n_{\mathrm{veg}}$ of $0.008 \mathrm{~m}^{-1 / 3} \mathrm{~s}$ was observed at a $V R$ value of $0.56 \mathrm{~m}^{2} / \mathrm{s}$, corresponding to a ratio between the water level and the undeflected plant height, $h / h_{\text {veg }}$, of $25 \%$, and an $R e_{p}$ value of $26.2 \times 10^{3}$.

The minimum values of $n_{\text {veg }}$ occurred at the lowest value of $V R, h / h_{v e g}$ and $\operatorname{Re}_{p}\left(n=0.004 \mathrm{~m}^{1 / 3} \mathrm{~s}\right.$ at $V R=0.18 \mathrm{~m}^{2} / \mathrm{s}, h / h_{v e g}=10 \%$, and $\operatorname{Re}_{d}=18.510^{3}$ ).

The undeflected submergence ratio is generally low, less than 0.4 for all flow conditions, which can be related to the geometry of plants (single stem) and to the tested density. Plants, in fact, did not significantly bend until $V R$ exceeded the value of 0.4 ; afterwards, the plants bent, and the deflected height became similar to the flow depth. At higher $V R$ values, the submergence ratio increased, but it could not be measured owing to the limitations of our experimental channel, in which we could not systematically observe the bent plant height and then evaluate with sufficient accuracy the changes of the vegetated layer thickness, as for example in Righetti (2008).

\section{Salix alba sessions}

The effect of white willow branches on the hydraulic resistance was always relevant but variable according to plant density and PAI.

The most flow-obstruent vegetation setup was the one used in session Salix alba (SA) 1 (which is the densest, although the PAI values were smaller than those in the other SA sessions; Table 2), with the estimated values of $n_{\mathrm{veg}}$ ranging between 0.044 and 0.067 $\mathrm{m}^{-1 / 3} \mathrm{~s}$. The range of $n_{\mathrm{veg}}$ is in agreement with Arcement and Schneider (1987), which would classify it as a very large effect, typical of moderate to dense brush.

The vegetation setups of sessions SA2 and SA3, which are rather similar except for PAI values (Table 2), resulted in similar ranges of $n_{\mathrm{veg}}$ values, between 0.023 and $0.041 \mathrm{~m}^{-1 / 3} \mathrm{~s}$. The obstruent effect of such configurations can be considered large and, according to Arcement and Schneider (1987), typical of 8- to 10year-old willow or cottonwood trees intergrown with some weeds and brush (none of the vegetation in foliage).

The vegetation setups of session SA4, which is denser than that of SA2 and SA3 and has a higher PAI value, resulted in a less obstruent effect with $n_{\mathrm{veg}}$ values ranging between 0,011 and 0.035 $\mathrm{m}^{-1 / 3} \mathrm{~s}$. The obstruent effect is classified as medium and typical of brushy, moderately dense vegetation, similar to 1- to 2-year-old willow trees in the dormant season (Arcement and Schneider, 1987).

In general, configurations with smaller plant density values induced similar resistance, regardless of the presence of leaves (Figure 3). SA4, in spite of a slightly higher density than that of SA2 and SA3, showed a minor effect at low values of $V R, h / h_{\text {veg, }}$, and $R e_{p}$, perhaps because the shrub used in SA4 was different from those used in the other experiments and possibly had a slightly different branching structure.

The results of all the sessions, except SA1 (the most flowobstruent), showed a two-stage trend in the $n_{\text {veg }} v s$. VR and $h / h_{v e g}$ and $R e_{p}$ relationships, with the position of the threshold point changing from one session to the next. This corresponds to a $V R$ value of approximately $0.3 \mathrm{~m}^{2} / \mathrm{s}$ for SA2 and SA3 and $0.5 \mathrm{~m}^{2} / \mathrm{s}$ for SA $4, h / h_{\text {veg }}$ of approximately $30 \%$ of the plant height in all experiments and a $R e_{p}$ value of approximately $1210^{3}$ for SA2 and SA3 and $2510^{3}$ for SA4. It must be underlined that the threshold values are similar for most configurations, except for SA4 and for SA1 (where only the decreasing trend was detected). Moreover, all the $n_{\mathrm{veg}} v s$. VR patterns tend to converge towards the same value of $n_{\mathrm{veg}}$ as $V R$ increases.
Finally, it is evident that for SA4 the trend of $n_{\text {veg values with }}$ $R e_{p}$ is different from the others as a consequence of a different branch diameter distribution (Table 2).

\section{Salix caprea sessions}

The results of the 32 experiments of the four Salix caprea (SC) sessions are shown in Figure 3 . In general, $n_{\text {veg values decrease }}$ passing from SC1 $\left(0.035\right.$ to $\left.0.068 \mathrm{~m}^{-1 / 3} \mathrm{~s}\right)$ to $\mathrm{SC} 2(0.025$ to 0.055 $\left.\mathrm{m}^{-1 / 3} \mathrm{~s}\right)$, SC3 $\left(0.016-0.032 \mathrm{~m}^{-1 / 3} \mathrm{~s}\right)$ and SC4 $\left(0.003\right.$ to $\left.0.017 \mathrm{~m}^{-1 / 3} \mathrm{~s}\right)$, according to plant density and PAI values. $\mathrm{SC} 1$, the vegetation setup with the highest density and PAI values, could be classified as having a large to very large effect, SC2 as large, SC3 as medium to large, and SC4 as small to medium (Arcement and Schneider, 1987).

The sessions show a variously marked two- stage trend, with

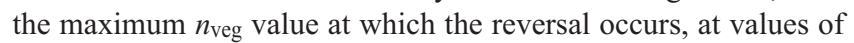
$V R$ of approximately $0.40 \mathrm{~m}^{2} / \mathrm{s}, h / h_{\text {veg }}$ of $30-40 \%(41 \%$ for $\mathrm{SC} 1$, $37 \%$ for SC2, $41 \%$ for SC3 and $28 \%$ for SC4) and $R e_{p}$ of $1410^{3}$. The falling phase is more pronounced in SC1, SC2 and SC3, whereas in SC4 a central flat portion can be observed. The $n_{\mathrm{veg}} v s$. $V R$ trends converge to a unique value of $n_{\mathrm{veg}}$ as $V R$ increases, as in the case of the SA sessions.

Comparing the SC1 and SC2 sessions, which have similar values of plant density and a small difference in PAI values (owing to the leaf presence in SC2), it can be noticed that the additional roughness component due to the presence of leaves is approximately $0.015 \mathrm{~m}^{-1 / 3} \mathrm{~s}$; the same value is obtained with a halved density when the branches are leafless (compare SC2, SC3 and SC4).

\section{Discussion}

The values of the additional Manning's coefficient obtained in our experimental sessions span over a wide range, depending mainly on plant species, density and partially foliage condition. The observed ranges of variability are consistent both with results from previous studies (e.g., Cowan, 1956; Chow, 1959; Bakry et al., 1992) and with the values suggested by technical literature (Arcement and Schneider, 1987). Within the same session, Manning's coefficient varied significantly for different flow conditions, proving that a constant, flow-independent value of the roughness coefficient is not adequate to describe the real behaviour of riparian vegetation, in contrast to what is frequently carried out in practical applications (e.g., Chow 1959). This confirms the results of small-scale laboratory experiments (Yen, 2002; Armanini et al., 2005; Rhee et al., 2008; Righetti, 2008), which, however, highlight only a part of the whole phenomenon. One of the main results of our full-scale experiments, in agreement with Freeman et al. (2000), is the evidence of a changing behaviour of partially flexible and partially submerged vegetation (Figure 3). This is particularly clear in the SC series, in which the implementation of the experiments benefitted from experience gained during the previous AG and SA sessions.

The results show that in all sessions except one (SA1), there is two-stage trend in the values of the additional hydraulic resistance at changing flow conditions, with the same vegetation setup. Initially, the hydraulic resistance increases with $V R, h / h_{v e g}$ and $R e_{p}$, as in the case of unsubmerged rigid bodies; then, after reaching a maximum, the resistance decreases with $V R, h / h_{v e g}$ and $R e_{p}$, as in the case of submerged flexible bodies.

Actually, at low flows, which are characterised by small water depth and velocity values, the vegetation is only partially sub- 

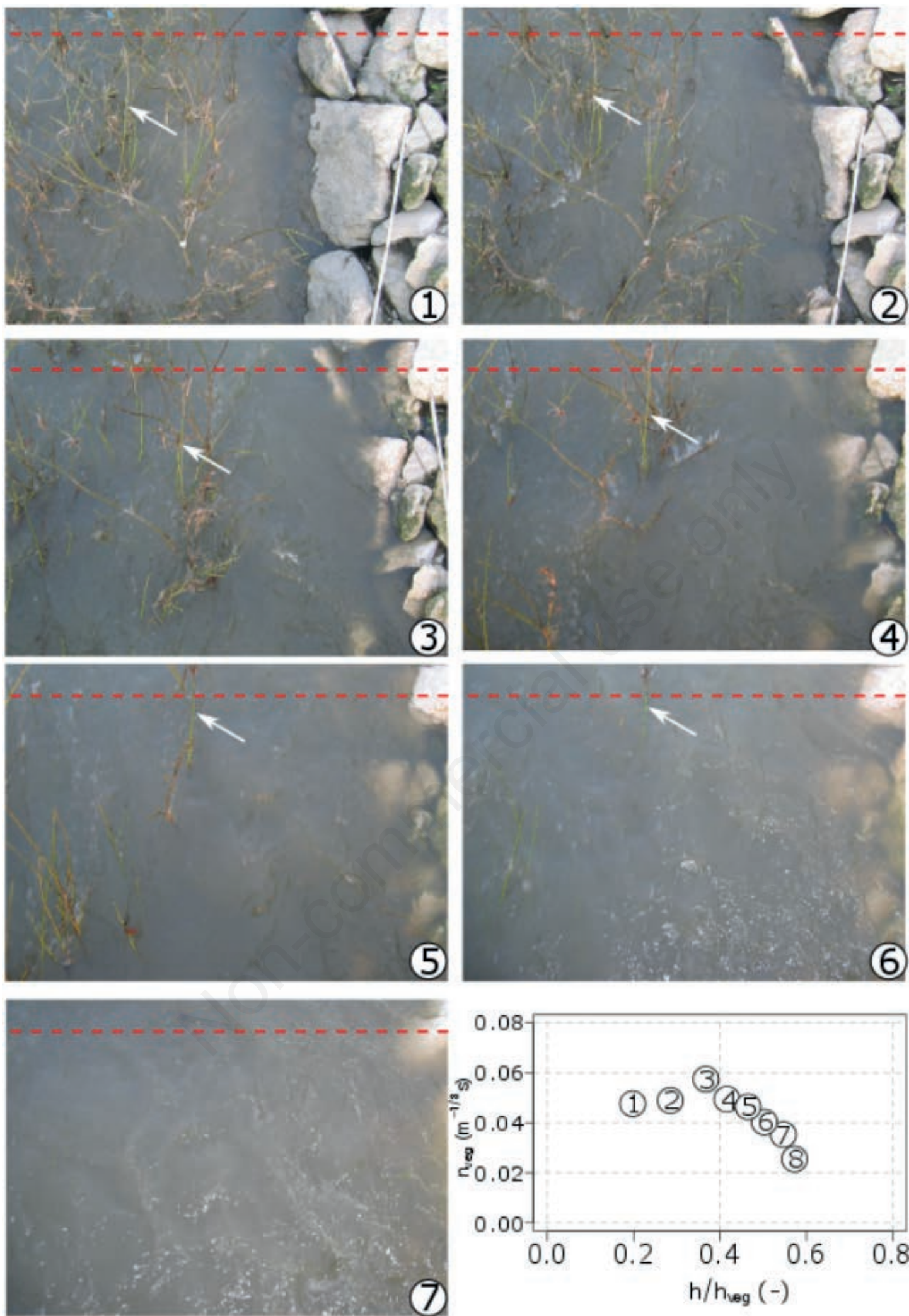

Figure 4. Plant bending with the increasing of the submersion. Numbers refer to the value of Manning coefficients in the chart at the bottom (i.e. SC2 series). Note that only part of the vegetation was submerged when the maximum roughness value is obtained (picture and point 3$)$. With the lowest discharge, the vegetation was weakly bended and it was stable (1); at higher discharge, stems were downstream orientated (2); then, vibration of stiff vertical stems and a sinuous movement of oblique or elongated horizontal stems occurred (3); stiff stems become more inclined (4); stems become prone or densely compacted (5); at the highest discharges, plants were completely submerged and bended at the bottom $(6,7$ and 8$)$. Use the red line as position reference. 
merged and the water flow impacts only on the stem and on the main branches, due to the typical distribution of branches and leaves along the height of riparian shrubs. Because the stem and the main branches are rather stiff, the resulting resistance behaves as in the case of rigid bodies. However, at higher flows both water height and water velocity increase and so does the force impacting on stems, main and minor branches and leaves; when it reaches a value that is sufficient to bend them, the plant tends to assume a more streamlined shape (Figure 4). The point at which these effects clearly emerge, marked as threshold point in the $n-V R, n-h / h_{\text {veg }}$ and $n-R e_{p}$ diagrams, is not fixed, although it varies in a rather small range, between approximately 0.3 and $0.5 \mathrm{~m}^{2} / \mathrm{s}$ for $V R$ and $30-40 \%$ for $h / h_{v e g}$. Freeman et al. (2000) reported a fixed position of the threshold point at $h / h_{v e g}$ of $80 \%$, based on the observation that, during the experiments, plants bent at this level of submergence. We believe that this difference in the threshold point position can be ascribed to the higher velocity values in our experiments, since the other conditions are similar in the two studies: the stiffness of the plants falls in the same range, the flow depth values are close and the hydraulic conditions sub-critical. It must be noted that in the SA1 session, where the vegetation setup consists of highly flexible branches, the two-stage trend of $n_{\text {veg }}$ did not emerge. This result occurs because the hydrodynamic force was sufficient to bend the branches already in the experiment with the smallest flow rate; therefore, only the second phase of the pattern could be observed, with the $n_{\text {veg }}$ values decreasing with increasing flow rate (Figure 4). As a consequence of such dynamics, the additional resistance due to plants deviates from the velocity-squared relationship typical of rigid bodies and decreases with velocity (Yen, 2002; Västilä et al., 2013).

The evidence of a two-stage trend of the of the $n v s$. velocity or submergence ratio relationship that emerges from our experiments is in agreement with the results of Freeman et al. (2000) and, to some extent, of Rhee et al. (2008), whereas other works on partially flexible vegetation observed only a reduction of resistance with velocity and/or submergence ratio (Västilä et al., 2013). This can be due to the differences in the scale of the experimental, the level of submergence and the branching structure of the vegetation used in the various studies. Our results, as well as those of Freeman et al. (2000), refer to full-size branches (1.0-2.0 $\mathrm{m}$ in height and 1$2 \mathrm{~cm}$ in diameter), under fully turbulent flow conditions, that are similar to those of real watercourses.

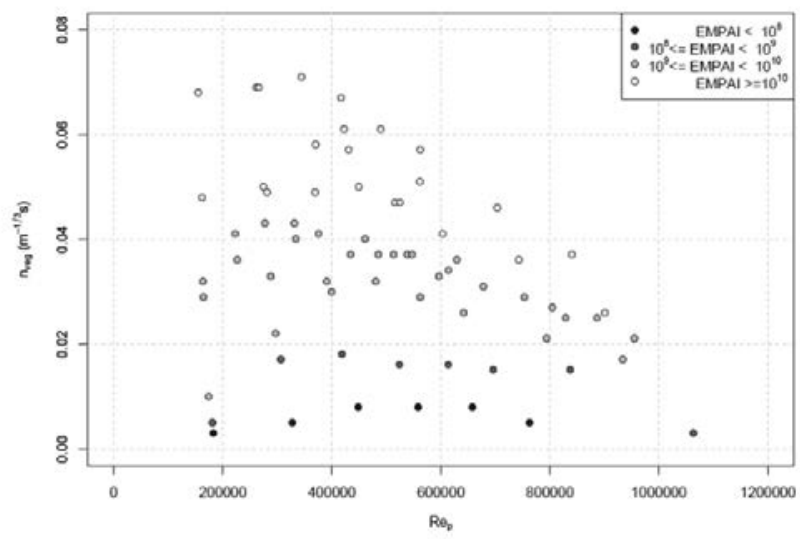

Figure 5. Values of $\mathbf{n}_{\mathrm{veg}}$ at changing $R \mathrm{e}_{\mathrm{p}}$; points are grouped in four classes of E·M·PAI values.
Armanini et al. (2005) and Righetti (2008) suggested consideration of a modified submergence ratio in which the bent plant height is taken instead of the full plant height. In our case, for practical reasons, it was impossible to measure such a deflected height; in any case, we deem that considering $h / h_{v e g}$ is better for practical applications ( $h_{\text {veg }}$ can be easily measured or estimated) and for comparison with most of the results already available in the literature.

The role of plant density emerged clearly, but it is not the single factor that determines the additional resistance due to riparian vegetation. Comparing the same species in the same leafless condition, but with a different plant density (also reflected by PAI values), as for SA1, SA2 and SA3 and SC2 and SC3, this role is evident (Figure 3 and Table 2 ). The difference in $n_{\mathrm{veg}}$ is approximately $0.03 \mathrm{~m}^{1 / 3} \mathrm{~s}^{-1}$ for SA and $0.015 \mathrm{~m}^{1 / 3} \mathrm{~s}^{-1}$ for SC passing from 14.8 to 2.6 plants $/ \mathrm{m}^{2}$ and from 18.0 to 11.7 plants $/ \mathrm{m}^{2}$, respectively.

The number of plants per unit area, however, is insufficient to characterise the vegetation. To consider plant characteristics, the friction factor was successfully normalised by LAI for the case of the foliated single-stem portion of plants (Västilä et al., 2013). In the case of multi-branch riparian vegetation, however, the process is more complex and LAI in unable alone to fully explain the roughness dynamics (Freeman et al., 2000). We then combined plant density (M), PAI and the modulus of elasticity (E), to account for the main factors affecting the additional resistance due to riparian vegetation. In Figure 5, the results of the experiments are grouped by the values of the product of the abovementioned variables $(\mathrm{E} \cdot \mathrm{M} \cdot \mathrm{PAI})$. It can be noted how $n_{\text {veg }}$ values increase with increasing combined index, and values with the combined index within the same order of magnitude can be grouped together.

Considering all our results (Figure 5), it can be noted that the values of additional $n_{\text {veg }}$ tend toward a unique value as $R e$ increases. This can be explained considering the characteristic of tested plants: branches bend and shrink as hydrodynamic forces impact them until a structural limit, related to the stiffness characteristics and topology of branches, is reached (Yen, 2002; Freeman et al., 2000; Armanini et al., 2005).

The role of leaves on the total resistance is significant and decreases with increasing $V R$ as a consequence of streamlining, as recently demonstrated by Västilä et al. (2013). At the same time, however, the experiments carried out with leafless plants demonstrate that the bending of the stem and the main braches is also fundamental within the dynamics of plants resistance. By comparing $\mathrm{SC} 1$ and $\mathrm{SC} 2$, in which the main difference is the presence of leaves in the latter, the difference in maximum $n_{\text {veg }}$ is $<20 \%$, whereas Västilä et al. (2013) estimated a difference between $60 \%$ and $70 \%$. In our case, however, plants are full-scale multiple branched shrubs, and the role of branch stiffness is greater than that in the small-scale single-stem plants used by Västilä et al. (2013). The topological structure and stiffness characteristics of plants, as a consequence, play a fundamental role in the flow-plant mutual interaction. Remarkably, in many climatic regions, riparian vegetation is deciduous and floods occur when plants are leafless, so that the additional resistance due to branches very likely exceeds the effect of leaves (Figure 4).

\section{Conclusions}

In this paper, we presented the results of full-scale experiments aimed to evaluate the hydraulic resistance due to partially flexible riparian vegetation, conducted under different hydraulic conditions and different plant configurations (species, density and leaf presence). 
The results show that riparian vegetation behaves differently under different hydraulic conditions as a consequence of changing plant-flow interaction. Riparian plants behave as a rigid body when $V R$ and/or $h / h_{\text {veg }}$ and/or $R e_{p}$ values are limited; consequently, resistance to flow increases. When a threshold value of $V R$ and/or $h / h_{v e g}$ and/or $R e_{p}$ is reached, the resistance decreases as a result of stem and branch bending and/or leaf-branch compaction; this process proceeds with increasing $V R$ and/or $h / h_{v e g}$ and/or $R e_{p}$. This twostage trend is in agreement with Freeman et al. (2000) and partially with Rhee et al. (2008) and is not captured by small-scale experiments. The threshold point in resistance values varies in a rather small range for significantly different plant densities and conditions (level of foliage) and seems to be related to the combined effect of stiffness, submergence ratio and flow velocity.

The plant characteristics (number, position and size of branches on the main stem) and the plant density seem to play a relevant role. In fact, when poorly branched plants at low densities are considered, resistance coefficient is small and differences between different hydraulic conditions are small too, since leaves and flexible minor branches already take an increasingly streamlined shape for small values of velocity (e.g., Västilä et al., 2013) and the effect of plants on the hydraulic resistance is nearly constant. On the contrary, when high-density vegetation conditions are analysed, the Manning's coefficient varies considerably at changing hydraulic conditions and the two-stage trend is well recognisable.

According to Västilä et al. (2013), foliage is a significant source of hydraulic resistance; from our experiments, this effect can be estimated on the order of $0.015 \mathrm{~m}^{-1 / 3} \mathrm{~s}$. Plant density, however, can be of great importance as well. In our experiments, when leafless plant densities were doubled, an increase of Manning's $n$ value on the order of $0.02 \mathrm{~m}^{-1 / 3} \mathrm{~s}$ was estimated.

We believe that these findings, which are based on full-scale experiments in terms of both plant size and flow characteristics, may contribute to improving the understanding of the interactions between flow and riparian vegetation; this understanding is fundamental for the design of riverbank soil bioengineering and stream restoration works and, more generally, for naturally oriented management of surface water bodies.

\section{References}

Arcement G.J., Schneider V.G. 1987. Roughness coefficients for densely vegetated floodplains. Water Res Investig Rep 834247, USGS, 34 pp.

Babaeyan-Koopaei, K, Ervine D.A, Carling. P.A., Cao Z. 2002. Velocity and Turbulence Measurements for Two Overbank Flow Events in River Severn, J. Hydraul. Eng. 128:891-900.

Bakry M.F., Gates T.K., Khattab A.F. 1992. Field-measurement hydraulic resistance characteristics in vegetation-infested canals. J. Irr. Drain. Eng. ASCE 118;2.

Bal K., Struyf E., Vereecken H., Viaene P., De Doncker L., de Deckere E., Mostaert F., Meire P. 2011. How do macrophyte distribution patterns affect hydraulic resistances? Ecol. Eng. 37. 529-33.

Bennett S.J., Simon A. 2004. Riparian vegetation and fluvial geomorphology. American Geophysics Union, Washington, DC, USA.

Bebina Devi T., Kumar B. 2016. Flow characteristics in an alluvial channel covered partially with submerged vegetation. Ecol. Eng. 94:478-92.

Carollo F., Ferro V., Termini D. 2005. Flow resistance law in channels with flexible submerged vegetation. J. Hydr. Eng. ASCE
131:554-64.

Chiaradia E.A. 2012. L'uso del plant area index per la determinazione del coefficiente di scabrezza della vegetazione arbustiva. In: XXXIII Convegno Nazionale di Idraulica e Costruzioni Idrauliche, Brescia, Italy.

Chow V.T. 1959. Open channel hydraulics. McGraw-Hill, New York, NY, USA.

Claessens H., Oosterbaan A., Savill P., Rondeux J. 2010. A review of the characteristics of black alder (Alnus glutinosa (L.) Gaertn.) and their implications for silvicultural practices. Forestry 83:163-75.

Dušek J., Květ J. 2006. Seasonal dynamics of dry weight, growth rate and root/shoot ratio in different aged seedlings of Salix caprea. Biologia. 61:441-7.

Errico A., Pasquino V., Maxwald M., Chirico G.B., Solari L., Preti F. 2018. The effect of flexible vegetation on flow in drainage channels: estimation of roughness coefficients at the real scale. Ecol. Eng. 120;411-21.

Eschenbach C., Kappen L. 1999. Leaf water relations of black alder [Alnus glutinosa (L.) Gaertn.] growing at neighbouring sites with different water regimes. Trees 14:28-38.

FISRWG. 1998. Stream corridor restoration: principles, processes, and practices. by the Federal Interagency Stream Restoration Working Group. (FISRWG) (15 Federal agencies of the US gov't). GPO Item No. 0120-A; SuDocs No. A 57.6/2:EN 3/PT.653.

Freeman G.E., Rahmeyer W.H., Copeland R.R. 2000. Determination of resistance due to shrubs and woody vegetation. Final report US Army Corps of Eng, Washington, DC, USA.

Green J. 2005. Comparison of blockage factors in modelling the resistance of channels containing submerged macrophytes. River Res. Appl. 21:671-86.

Järvelä J. 2004. Determination of flow resistance caused by non-submerged woody vegetation. Int. J. River Basin Manag. 2:61-70.

Kirkby J.T., Durras S.R., Pitt R., Johnson D. 2005. Hydraulic resistance in grass swales design for small flow conveyance. J. Hydr. Eng. ASCE 131:65-8.

Kothyari U.C., Hayashi K., Hashimoto H. 2009. Drag coefficient of unsubmerged rigid vegetation stems in open channel flows. J. Hydraul. Res. 47:691-9.

Li Y., Wang Y., Ofosu Anim D., Tang C., Du W., Ni L., Yu Z., Acharya K. 2014. Flow characteristics in different densities of submerged flexible vegetation from an open-channel flume study of artificial plants. Geomorphology 204:314-24.

Merritt D.M., Scott M.L., Poff N.L., Auble G.T., Lytle D.A. 2010. Theory, methods and tools for determining environmental flows for riparian vegetation: riparian vegetation-flow response guilds. Freshwater Biol. 55:206-25.

Ming R.H., Shen H.W. 1973. Effect of tall vegetation on flow and sediment. J. Hydr. Div. ASCE 99:793-814.

Musleh F.A., Cruise J.F. 2006. Functional relationship in wide flood plains with rigid unsubmerged vegetation. J. Hydr. Eng. ASCE 132:163-71.

Nepf H.M. 2012. Hydrodynamics of vegetated channels. J. Hydr. Res. 50:262-79.

Pusey B.J., Arthington A.H. 2003. Importance of the riparian zone to the conservation and management of freshwater fish: a review. Marine Freshwater Res. 54:1-16.

Rhee D.S., Woo H., Kwon B.A., Ahn H.K. 2008. Hydraulics resistance of some selected vegetation in open channel flows. River Res. Appl., 24: 673-87.

Righetti M. 2008. Flow analysis in a channel with flexible vegetation using double-averaging method. Acta Geophys. 56:801-23. 
Righetti M., Armanini A. 2002. Flow resistance in open channel flow with sparsely distributed bushes. J. Hydrol. 269:55-64.

Sellin R.H.J., Bryant T.B., Loveless J.H. 2003. An improved method for roughening floodplains on physical river models. J. Hydr. Res. 41:3-14.

Stone B.M., Shen H.T. 2002. Hydraulic resistance of flow in channels with cylindrical roughness. J. Hydr. Eng. ASCE 128:500-6.

Subhash C.J. 2001. Open-channel flow. John Wiley and Sons ed., New York, NY, USA, 328 pp.

Temple D.M. 1999. Flow resistance of grass-lined channel banks. Appl. Eng. Agric. 15:129-33.

Västilä K., Järvelä J., Aberle J. 2013. Characteristics reference area for estimating flow resistance of natural foliated vegetation. J.
Hydrology 492:49-60.

Wilson C.A.M.E., Stoesser T., Bates P.D., Batemann Pinzen A. 2003. Open channel flow through different forms of submerged flexible vegetation. J. Hydraul. Eng. 129:847-53.

Wu F-C., Shen H.W., Chou Y-J. 1999. Variation of roughness coefficient for unsubmerged and submerged vegetation. J. Hydr. Eng. ASCE 125:934-42.

Yagci O., Tschiesche U., Kabdasli M.S. 2010. The role of different forms of natural riparian vegetation on turbulence and kinetic energy characteristics. Adv. Water Resour. 33:601-14.

Yen B.C. 2002. Open channel flow resistance. Hydr. Eng. ASCE 128:20-39. 